\title{
Multilingual Repertoires at Play: Structure and Function in Reported Speech Utterances of Alyawarr Children
}

\author{
Sally Dixon (1)
}

check for updates

Citation: Dixon, Sally. 2021.

Multilingual Repertoires at Play: Structure and Function in Reported Speech Utterances of Alyawarr Children. Languages 6: 79. https:// doi.org/10.3390/languages6020079

Academic Editors: Elisabeth Mayer Carmel O'Shannessy and Jane Simpson

Received: 31 January 2021

Accepted: 19 April 2021

Published: 23 April 2021

Publisher's Note: MDPI stays neutral with regard to jurisdictional claims in published maps and institutional affiliations.

Copyright: (C) 2021 by the author. Licensee MDPI, Basel, Switzerland. This article is an open access article distributed under the terms and conditions of the Creative Commons Attribution (CC BY) license (https:/ / creativecommons.org/licenses/by/ $4.0 /)$.
School of Humanities, Arts, and Social Sciences, University of New England, Armidale 2350, Australia; sally.dixon@une.edu.au

\begin{abstract}
While there is increasing international interest in approaching language analysis with the prism of repertoire, research on repertoire on the Australian continent is still very much in the shadow of "traditional" language-centric documentary work. This paper will explore the question of how users of Australian, English-lexified contact varieties exploit their multilingual repertoires to achieve local, conversation-organizational ends. Drawing upon a corpus of video recordings from Ipmangker, a Central Australian Aboriginal community, and using the analytical methods of interactional and comparative variationist linguistics, I examine the production of reported speech by four 6- to 7-year-old Alyawarr children in a play session at home. A set of prosodic, phonological, morphological and discourse-pragmatic features are shown to form a coherent set of linguistic elements with which these multilingual children can contrast reported speech from the surrounding talk. Moreover, the use of reported speech in play not only allows the children to organize their interaction, but responds to and constructs the epistemic landscape of play.
\end{abstract}

Keywords: Alyawarr English; multilingual repertoires; reported speech; child language

\section{Introduction}

One of the enduring features of language use on the Australian continent is widespread multilingualism, both individually and in the community. Prior to colonial invasion, there were at least 250 languages spoken on the Australian continent, by traditional reckonings (Dixon 2002, p. 2), and individual multilingualism was the norm (Harris 2007; Rumsey 2018). This continues today, although in a radically altered linguistic landscape (McKay 2007). In communities where traditional Australian languages are still spoken, postinvasion contact languages have also emerged. The most widespread of these, Kriol, is spoken by around 20,000 people across the northernmost parts of the Northern Territory and Western Australia (Schultze-Berndt et al. 2013). Several other Creole varieties (Torres Strait Creole, e.g., Shnukal 1991; Cape York Creole, e.g., Crowley and Rigsby 1979), mixed languages (Gurindji Kriol, e.g., Meakins 2015); Light Warlpiri, e.g., O'Shannessy (2013), dialects of English (Aboriginal English, e.g., Eades 2014), and others (such as Wumpurrarni English, e.g., Disbray 2008; and various Queensland contact varieties, e.g., Sellwood and Angelo 2013) have proliferated in the many varied, and often imposed, sites of sustained language contact since colonial invasion ${ }^{1}$.

Research on these new varieties has tended to progress in the general tradition of fieldwork-based linguistic description. As such, we have descriptions of Kriol, Light Warlpiri, Gurindji Kriol, and Torres Strait Creole, and understand better, for example, the grammatical properties and contextual elements of their genesis that allow them to be classified as creoles or mixed languages. At the same time that this work has progressed, documentation and description of traditional Australian languages have also continued apace.

\footnotetext{
1 See Meakins (2015) and Meakins and O'Shannessy (2016) for a recent comprehensive overview.
} 
In each of these studies, the speakers of the variety in focus are in fact multilingual. Since the 1970s, every Indigenous child has been through formal education, been taught predominantly in Australian English, and has added that variety to their individual repertoires. In the Kriol zone, many older people still speak traditional Australian languages, and younger generations have varying proficiency in the languages of their elders. Yet describing these repertoires of language use has not been the center of as much academic activity in Australianist linguistics, which still favors a language-centric approach to explorations of language structure. Research that has foregrounded multilingualism has produced rich descriptions and understanding of practices, rather than structure per se. For example, an incomplete selection might highlight themes such as the social contexts and function of code-choice and code-switching (Elwell 1977, 1982; McConvell 2008; Mushin 2010; Wilson et al. 2018), the sociocultural dynamics of multilingualism in historical reconstructions (Rumsey 2018), speaker ideologies (Singer and Harris 2016; Vaughan 2018), multilingual identities (Brandl and Walsh 1982), conversation management (Mushin 2010) and narrative construction (Evans 2010). The current study proposes a way to marry descriptions of both linguistic structure and multilingual practices, and that is by reversing the focus from describing varieties to describing repertoires. To achieve this, the structure and function of reported speech utterances in the pretend play of multilingual primary school-aged children are examined and situated within descriptions of how different components of their multilingual repertoire are deployed for other purposes.

The term 'repertoire', closely associated with scholars in the Gumperz-Hymes tradition, has been described as one of the 'basic sociolinguistic concepts' (Gumperz [1972] 1991, pp. 20-21). It refers to the "totality of linguistic resources (i.e., including both invariant forms and variables) available to members of particular communities" (Gumperz [1972] 1991, pp. 20-21). The focus of analysis in this tradition has centered on illuminating not only the range of distinct language varieties (languages, dialects, registers, styles) that an individual or speech community possesses, but also the range of uses to which they are put (e.g., from the range of verbal arts (Gumperz 1982) to the inventory of everyday communicative acts that is the focus of related fields such as Interactional Linguistics). The description of repertoire has received little attention in the Australian context (however, see O'Shannessy (2015); Dixon (2017); Vaughan (2018); and Meakins (2020)).

Over the last few decades, a number of critiques of the language-centric skew in linguistics have emerged. Makoni and Pennycook (2007) explore how viewing languages (and their speakers) as "bounded" entities served the colonial project, by drawing a link between census-making and control: peoples that are countable are controllable. Otsuji and Pennycook (2011) advance the idea of metrolingualism as a disruption to "enumerative" framings of multilingualism that view multilingual repertoires as "plural monolingualism" (p. 415). The concept of "translanguaging" challenges and displaces framings of multilingual language use that rest on code-discreteness, and the multilingual as having multiple monolingual competencies (García and Wei 2014). These approaches can be termed repertoire-centric, to contrast with and complement language-centric approaches.

The assumptions of a repertoire-centric perspective on language are well articulated by Matras ([2009] 2020, p. 4). Multilinguals are understood to "have a complex repertoire of linguistic structures at their disposal", and this repertoire "is not organized in the form of 'languages' or 'language systems'"; these are labels language users and linguists alike are socialized to apply post hoc. Rather, "elements of the repertoire (word-forms, phonological rules, constructions and so on) gradually become associated ... with a range of social activities, including factors such as sets of interlocutors, topics, and institutional settings." This echoes the earlier framing of Gumperz, who also argues that the varieties that compose a multilingual repertoire "form a behavioral whole, and must be considered constituent varieties of the same verbal repertoire" (Gumperz 1964, p. 140).

This framing of the multilingual repertoire has much in common with the conceptualization of linguistic systems as advanced in the research tradition of variationist sociolinguistics. The main focus of this approach has been on variation within and between related 
varieties $^{2}$, and the main unit of analysis has been the linguistic variable: language elements that have "more than one way of doing the same thing" (Labov 1972), or communicatively equivalent structures that have come to be associated with different social activities (to recast this in Matras' terms). For example, the seminal works of Labov (collected in Labov [1966] 2006) on the New York English speech community demonstrated how a cluster of variables showed both social and stylistic stratification. That is, in a given setting, for a given purpose, a particular type of speaker would predicably use a set of variants to mark their speech as formal/informal, as well as to index their social status. This demonstrates how researchers look for clusters of variants that correlate and covary at the individual and community level. This co-variance has been termed "coherence" (e.g., see Guy and Hinskens (2016) for a recent exploration of the history of research into this phenomenon).

While Matras' concern is primarily that of elucidating the process of language contact, and variationists have been traditionally focused on how language variation serves the social lives of its users, they are kindred spirits when it comes to the fundamentals. Firstly, to understand one part of the repertoire (i.e., one 'language' or variety or style) we must understand the rest; a language repertoire is a kind of linguistic gestalt (or "alloy" (Alvarez-Cáccamo 1998, p. 39)) with no part of an individual's repertoire ever "turned off". Both approaches position "varieties" as composed (from a range of options) and contingent (on social-contextual factors). Secondly, and following on from this, the essential descriptive task of the linguist is to understand which kinds of "social activities" (including considerations such as interlocutors, topics, institutional settings, etc.) become associated with which kinds of covarying or cohering linguistic elements.

Previous research has indeed shown that a range of situational factors can prompt language users to select from contrastive elements in their language repertoires. For example, even very young bilingual children (by the age of 2 years) make language selections based on the language use of their interlocutor (e.g., Genesee et al. 1995). Beyond these kinds of macro-contextual aspects, language selection has also been shown to align with more moment-by-moment, micro aspects of the interactional context, particularly in the construction and management of "social actions" such as repair and dispreferred response-making (e.g., Li and Milroy 1995) and reported speech (e.g., Auer 1984, 1995; Gafaranga 2007). For example, Auer (1984) approaches direct speech reporting from within his schema as discourse-related transfer. That is, it is not intended to interrupt the overall language of interaction, and essentially functions to provide a contrast between the two speakers: "setting off of reported speech against its conversational (often narrative) context" (Auer 1995, p. 119). This research shows that it is possible to look deep into the interaction itself to find prompts for repertoire selection.

To bring this exploration of the multilingual repertoire to the Australian continent, the present study examines the language practices of a group of young Alyawarr children located in a remote community of Central Australia (more in the following section). The primary research question is: What "social activities" exist in these children's multilingual repertoires, and with which clusters of covarying or "cohering" linguistic elements have they become associated?

Once the relevant social activities are mapped out, this serves as the basis for a deeper exploration of the multilingual repertoire, in particular, for understanding why children might alternate selection from different parts of their repertoire in a given interaction. As Matras ([2009] 2020, p. 4) states "[c]ontext-appropriate selection does not necessarily conform to a separation of 'languages': In some contexts, certain types of cross-linguistic 'mixing' and 'inserting' may be socially acceptable and may constitute effective goaloriented communication." The wealth of literature on the use of code-switching and code-mixing attests to the pervasiveness of this aspect of how multilinguals deploy their repertoires. A second research question then arises: What does selecting from different

2 However, see, for example, Torres-Cacoullos and Travis (2018) for recent developments in the comparison of unrelated varieties in close contact, under the rubric of 'Variationist Typology'. 
parts of the multilingual repertoire afford these children in the context of play? In other words, how does cross-linguistic mixing in play constitute, in Matras ([2009] 2020, p. 4) formulation, "effective goal-oriented communication"?

I will first present a description of the process by which the multilingual repertoire in question was captured before moving on to a description of how various linguistic elements cluster in the performance of particular social activities. Following this, I will examine how this deployment of the multilingual repertoire constitutes "effective, goal-oriented communication" (Matras [2009] 2020, p. 4), before moving on to discuss these findings.

\section{Materials and Methods}

The setting for this study is the Ipmangker Community, a small Aboriginal community on the border fringe of the traditional lands of the Alyawarr and Kaytetye peoples, in Central Australia. Data for this study are taken from the Ipmangker Corpus (Dixon 20092011), which consists of 50+ hrs of naturalistic video recordings, set in a range of home and school contexts. The corpus centers on six focus children, four girls and two boys, aged between 5 and 8 (plus their relatives and classmates who happen to appear, with permission, "in the frame"). This corpus also includes a small collection of adult Alyawarr English narrative and conversational speech. This corpus was compiled by the author, with transcription assistance from two community-based Alyawarr research assistants, Ms. Michelle Dobbs and Ms. G. Kelly (now deceased), over several extended visits in the community across a time span of two years. Data used in this study were transcribed in ELAN.

The children in the study are multilingual and live in a multilingual language ecology. The elders in Ipmangker Community speak a number of Australian languages, particularly Alyawarr, Kaytetye and Warlpiri, as well as English. Over the past 30 years, a new contact variety has emerged in Ipmangker, which we are referring to as Alyawarr English for the purposes of publication. Alyawarr English shows evidence of a variety of source languages: Australian English, Kriol (Schultze-Berndt et al. 2013), Central Australia Aboriginal English varieties (Koch 2000; Malcolm and Kaldor 1991), and Alyawarr, a Pama-Nyungan language of the Arandic sub-group (Yallop 1977). The focus children in this study appear to have acquired Alyawarr English as their first language, as well as at least passive understanding of Alyawarr and/or the other traditional languages. They then begin to formally acquire Australian English when they begin preschool in the community at around the age of $4-5$ years.

The corpus was composed to explore the emerging multilingual repertoire of young children in Ipmangker. This was done by following the focus children across typical days as they moved between home and school and recording a representative selection of activities. As such, the corpus captures the linguistic repertoire of each focus child, as well as the range of interactional tasks they undertake with that repertoire. Previous research using this corpus partitioned the corpus into two sub-corpora: a HOME dataset, composed of utterances recorded when children were interacting at home with each other, and a SCHOOL dataset, composed of utterances recorded when the children were at school and addressing a non-Indigenous teacher (Dixon 2017, 2018). A comparison was then made by focusing on variable features in the children's repertoire, following the variationist comparative method (Poplack and Tagliamonte 2001). This approach to corpus-building and analysis therefore starts with an assumption around some of the factors that distinguish two relevant social activities (talking to a teacher at school, and talking to a peer at home) to enter the bilingual repertoire.

This methodology also marks a departure from traditional, language-centric approaches to language description, which typically puts the burden on the analyst to (at least partially) circumscribe what constitutes a particular language before analysis of its structure has begun. In the context of highly multilingual Indigenous Australia, linguists have had to impose some criteria in order to sort and select utterances from the multilin-

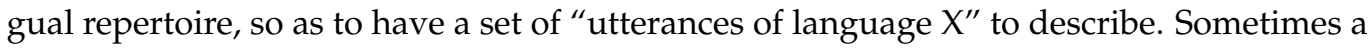


conceptual framework such as the Myers-Scotton matrix frame model, for example, could be applied to deal with language strings that appear to involve code-switching (e.g., Meakins 2007). Alternatively, the norms of a group of monolingual speakers (such as culturally dominant speakers of Australian English) or those of a standardized variety (such as Standard Australian English) act as a benchmark to determine whether something is or is not the "English" part of a speaker's repertoire. The use of monolingual adult speech norms as a benchmark is the dominant one in broader bilingualism research (particularly on multilingual child language use).

This approach to language description becomes methodologically challenging when dealing with multilingual repertoires in which the varieties are closely related. There will be plenty of utterances in the multilingual corpus that are acceptable in both varieties. This is the case in the present research, as the following pair of examples illustrates ${ }^{3}$.

1. Am kliningap, reken.

$\begin{array}{lll}\text { Am } & \text { klin-ing-ap } & \text { reken } \\ \text { 1SG.SBJ } & \text { clean-ING-ADV } & \text { reckon }\end{array}$

'I'm cleaning up, (I) reckon.'

[SJD-040:907 Tiffany home; cleaning up toy plates and meal items]

2. En ai go bek.

En ai go bek

And 1SG.SBJ go back

'And I go back.'

[SJD-062:1154 Deanna home; moving toy car along ground]

Both of these utterances were taken from the Ipmangker Corpus. They are grammatical from the perspective of both Standard Australian English and the contact variety spoken by adults in that community. There are some aspects of the phonological realization that distinguish the utterances from equivalent productions by culturally dominant, ethnically white speakers of Australian English. However, these accent features largely prevail when children are clearly "targeting" Australian English (such as when talking to non-Indigenous teachers at school). Thus, if a linguist wished to analyze only one variety in these children's repertoires, it would be unclear to what data set these utterances should be assigned: Australian English or Alyawarr English. By sorting data in terms of the social activities they are doing, however, this problem of pre-empting the meaning of structural differences is avoided.

For the present study, I examined a set of utterances that were not included in the initial analysis of the HOME and SCHOOL datasets. These were excluded because, while they fit the basic HOME criteria (at home, talking to another child), they seemed to contain a cluster of linguistic elements that differentiated them from the other HOME talk, and made them, impressionistically, more like the SCHOOL data. They also all shared the same, more specific, function: they were utterances during reported speech, in this case voicing the utterances of Polly Pocket ${ }^{\mathrm{TM}}$ dolls that the focus children were playing with.

Reported (or "indirect") speech, broadly definable as using language to report language (to paraphrase several others, e.g., Holt and Clift 2007, p. 1), has been the focus of much research from a number of different areas of linguistics. I will highlight some of the findings most relevant to the present study. One of the key themes in pragmatic accounts ${ }^{4}$ has been the role of reported speech components in "footing" (Goffman 1981; Levinson 1988; Frick and Riionheimo 2013) or stance-taking (Schegloff 1984; Clift 2006). The manner in which the original language production is reported can reveal the particular orientation of the person doing the reported speech to either the original speaker or the content of the

3 Reported speech utterances are transcribed using the orthographic conventions of Australian English. Talk surrounding the reported speech utterances are transcribed using an adapted version of the Kriol orthography, a widely used orthography developed for creoles in the Northern Territory and the Kimberley, and later also applied to mixed languages in the region (Schultze-Berndt et al. 2013).

4 See Holt (2009) for an in-depth overview. 
production, or both. Moreover, reported speech components have been shown to be used in specific ways to "heighten evidentiality" (Couper-Kuhlen 2007, p. 82), that is, to present an event as more "true" by an authentic representation, and in doing so to claim authority in social actions such as assessment-making (Clift 2007). Research that focuses on the structural properties of reported speech has examined the design features of reported speech utterances, and grappled with whether this is enough to constitute reported speech as a "dedicated syntactic domain" (Spronck and Nikitina 2019; see also response papers in the same issue). The design properties of reported speech have also featured in Interactional Linguistics accounts, in concert with sequential positioning, to contemplate the various interactional functions of second-hand talk (e.g., in doing complaints, per Haakana 2007; and assessments and accounts, per Couper-Kuhlen 2007).

In the context of children's language use, reported speech has featured in a variety of interactional contexts, from monolingual children's performance of authenticity in the reporting of conflict (Theobald and Danby 2012) to multilingual children's deployment of code-switching in "role utterances" in role play (Kleemann 2013; Halmari and Smith 1994).

The reported speech utterances under examination here occurred in a single video recording of around $50 \mathrm{~min}$ duration. In the play session are four young girls: Lucy 7;8, Alysha 7;5, Tiffany 7;0, Deanna 6;8. These children had been recorded by the author on multiple occasions at home and school over the preceding 2 years. Additional audio was captured using a Zoom H4 recorder and Sennheiser lapel microphone (worn by Lucy). This particular play session yielded 1427 utterances (intonation units) in total, with 197 reported speech utterances, ranging in length from 1 to 8 words in length. The recording was transcribed in ELAN, using both the video and enhanced audio channels. Reported speech utterances and surrounding episodes of talk and action were transcribed and analyzed closely, using the conventions of Interactional Linguistics with one addition to the established transcription conventions: reported speech utterances appear in quotation marks (" ").

The period in which the girls are playing with the dolls develops a particular rhythm, alternating between periods of animated play and other interactions. Animated play is characterized by the following:

1. narrating the actions of dolls (called "directory utterances" by Kleemann 2013), e.g., Ai bin luk lang kabad na reken "I looked in the cupboard now, reckon";

2. asserting characteristics of the setting, e.g., Wi ol frend-rnem nanti "We're all friends, aren't we"; and

3. voicing what the dolls are saying to each other (i.e., performing reported speech).

Periods of "other" talk (or "out-of-play" talk, per Kleemann 2013) deal with conflict, discussing how to manipulate the dolls (such as how to put different clothes on the dolls), and finding misplaced toy items. The proportion of animated play increases over time as talk dealing with logistics dissipates.

\section{Results}

In this section I outline some of the distinctive structural aspects of the reported speech utterances, including prosodic and phonological aspects, morphological aspects, and discourse framing. In doing so, I will sketch a picture of the linguistic elements that have come to be associated with reported speech. In the presentation of this data analysis, comparisons will be made to both the HOME and SCHOOL datasets. Recall that the reported speech utterances were not previously assigned to either the HOME or SCHOOL data; they were excluded from analysis altogether. From this two-way comparison, we can determine whether reported speech utterances are constructed from the same set of linguistic elements as in the SCHOOL (talking to a non-Indigenous adult in the school) or HOME (talking to another Alyawarr person at home) contexts, or whether they are constructed from a different combination of linguistic elements altogether. 


\subsection{Prosody}

There are distinct prosodic aspects to the reported speech which make them unlike the surrounding HOME talk and the Australian English that the children use in SCHOOL contexts. These utterances tend to be at a higher overall pitch than surrounding talk, have a slower rate of speech, and frequently have exaggerated expression and clause intonation. All of these are evident in the reported speech utterances on lines 574, 578, 580 and 582 of Extract 1.

\section{Extract 1}

573 Alys ye ai bin dresimapbatself reken, Yeah, I dressed myself reckon

(.)

$574 \quad$ Alys $\quad<$ “Where's? my, ^high shoes.">

575 Alys Ba arew, themab bin iya haiding ^daun reken, But look, they were hiding down here, reckon.

577 Alys Laiya main bratha ai bin tisimbat reken, Pretend, my brother was teasing (me), reckon

578 Alys < “Where is it,">

579 Alys $\quad>$ Ai bin askimbat, $<$ I was asking

(.)

581 Alys $>$ En ai bin fain tha ring na reken<, en- ai bin tok, And I found the ring now, reckon, and I said

(.)

○"How we gonna put the $\uparrow$ ri: $\downarrow$ ng,"

\subsection{Phonology}

In terms of phonological variation, Alysha's reported speech utterances stand out as the most contrastive with surrounding talk. In fact, some of these give a north American flavor to her speech. There are three specific features that give this effect: rhoticity and the lowering of the back vowels /o:/and/o/.

The English spoken by the children in the Ipmangker corpus (both in HOME and SCHOOL contexts) is generally non-rhotic. That is, / $\mathrm{I} /$ is not produced in pre-pausal or pre-consonant positions (as with other varieties of Australian English, see Cox and Palethorpe (2007)). In the previous example, Alysha produces where with the alveolar approximant in lines 574 and $578^{5}$.

Rhoticity is also noticeable in some clause-final positions, such as on water:

3. "Wow! This look amazing wate/I/"

[SJD-069: Line 1049, Alysha]

Rhoticity is not confined to contexts in which the rhotic is produced in General American (or represented in Australian English orthography). For example, the realization of $i d e a$ in the following is rhotic. This can be understood as an instance of hyper-rhoticity.

4. "I got idea/I/to talk about it"

[SJD-069: Line 1248, Alysha]

5 Note that many speakers of Australian English varieties have linking / $r$ / across word boundaries, which would make the rhotic realization on line 578 more typical. However, there is a micro-pause (of $0.1 \mathrm{~ms}$ duration) between the words where and is, so this is not a case of connected speech. 
Another phonological feature that distinguishes Alysha's reported speech utterances from the surrounding talk is the tendency for the back vowels /o:/and/\%/ to be lowered towards the General American realization /a/.

Compare the following two examples: god and not, with the former (example 5) an example of reported speech.

5. "Oh my g/a/d"

[SJD-069: Line 268, Alysha]

6. $\mathrm{N} / \mathrm{s} / \mathrm{t}$ alakenh.

not alahenth

not like.that

'Not like that'. [SJD-069: Line 1062, Alysha]

Here are examples of the same lexeme talk realized as /a/ in the reported speech utterance (example 7) and as /o: / in surrounding talk (Example 8).

7. "I need to $\mathrm{t} / \mathrm{a} / \mathrm{k}$ about it"

[SJD-069: Line 805, Alysha]

8. Yumab alweis $\mathrm{t} / \mathrm{o}: / \mathrm{k}$ 'nor' tu

yumab alweis tok nor tu

2pl always talk nor too

'You say 'nor' too.'

[SJD-069: Line 324, Alysha]

These observations about phonological differences appear mainly in the speech of Alysha. The three other girls produce reported speech utterances that are prosodically distinct but are less so phonologically. It is also important to note that these features do not characterize Alysha's SCHOOL English, which suggests that reported speech is not simply "switching to Australian English". The choice of more General American phonological and prosodic variants could be part of the construction of the characters of these dolls: perhaps they are being constructed as American. It could also arise from the fact that the use of these features serves to increase the contrast between the reported speech elements and the surrounding talk. Previous works on code-switching have suggested that "in order for the switch to be salient enough to function as a contextualization cue, it cannot be (a) gradual, (b) phonetically and morphologically integrated, or (c) mixed-coded, but needs to occur abruptly between two clearly distinct codes" (Frick and Riionheimo 2013, p. 5876). The use of rhoticity in particular, which contrasts General American English from both Australian English and Alyawarr English, serves to increase the distinction between reported speech and surrounding talk.

\subsection{Lexicon}

Although Alyawarr English (AlyE) shares a large proportion of its lexical items with Australian English, one point of contrast is that AlyE incorporates some Alyawarrderived lexicon. In the current recording, a number of Alyawarr-derived lexemes appear. These are presented in Appendix A. In the reported speech utterances, these Alyawarrderived lexemes are not used (except in one instance that I will discuss below). Rather, the equivalent English lexeme is used instead. For example, in Extract 2, the girls are talking about the dolls' hat accessory. Lucy is doing reported speech (in lines 1263 and 1265) and uses the lexeme hat on both occasions. By contrast, Alysha is looking for a hat of her own and uses the Alyawarr-derived lexeme mwekart "hat" when speaking as herself (not doing reported speech). In extract 3, Alysha uses the lexeme water (line 1049) when doing reported speech, and less than a minute later Tiffany uses the Alyawarr-derived equivalent kwaty (line 1067) when talking as herself.

6 Frick and Riionheimo's (2013) study of Finnish-Estonian code-switching in reported speech actually found that such strict separation was not necessary, which in general aligns with the present research, insomuch as Alyawarr English and Australian English are closely related varieties with substantial structural overlap. 


\section{Extract 2 \\ 1262 Lucy <“个Ye::s:: Can I $\uparrow$ help you- Uhhhh!"> \\ $(0.8)$ \\ 1263 Lucy <"Mine ha:t!"> \\ (2.5) \\ 1264 Alys Weyas mai mw- (0.1) $\uparrow$ weyas mai mwekart \\ bwegart? \\ Where's my h-(0.1) where's my hat bat \\ (2.3) \\ 1265 Lucy <"Mine H[A::T!"> \\ 1266 Alys [yuna crai Deanna ((laughs)) weya tha mwe- kart,}

Extract 3

1049 Alys <个“Wo::w this look ama:zing w-((hiccups)) water.” $>$

1068 Tiff > Irrepern-akely reken<

$[\ldots 50 \mathrm{~s} \ldots]$

1067 Tiff >>Thisan go kwaty-itwew reke:::.::n, $<<$

This one goes to the water, reckon

Another kind of lexical variation is between English-derived Alyawarr English lexemes that contrast with Australian English lexemes. One case of this is in the variation between high shoes meaning "high heels" and shoes. In Extract 4, Alysha's doll compliments Lucy's doll on her shoes, calling them high shoes (line 1226). Tiffany appears to take issue with this, repeating high shoes followed by the discourse particle reken. This appears to function as a repair initiation, per the next-turn proof procedure (Hutchby and Wooffitt 1998, p. 15); the repair is provided by Alysha herself in the following line: high shoes is repaired to shoes. This could indicate some awareness that high shoes is not quite the right Australian English lexeme, despite the fact that high heels would be the lexical equivalent and not shoes.

\section{Extract 4}

$\begin{array}{lll}1226 & \text { Alys } & \begin{array}{l}\text { "I like your high shoes" } \\ (0.2)\end{array} \\ 1227 & \text { Tiff } & \text { high shoes re[ken } \\ 1228 & \text { Alys } & \text { ["I mean shoes" }\end{array}$

These girls therefore demonstrate some lexical control when it comes to the production of reported speech, such that, when contrastive lexical pairs exist, the more Australian English lexeme is preferred, and the Alyawarr-derived or English-derived Alyawarr English lexeme is dispreferred and avoided.

\subsection{Morphology}

The morphological elements canvassed in the following sub-sections were chosen because they have been shown to be variable in the children's language repertoires (see Dixon 2017, 2018). In the Labovian variationist tradition, intraspeaker variables are ones that have multiple associated variants, from which speakers select in predictable although probabilistic ways. The conditions constraining this variation can be linguistic (i.e., other aspects of the clause) and external (such as interlocutor, formality, etc.). In previous research, these girls were shown to vary their use of several morphological variables by contextual 
factors (at HOME versus at SCHOOL) and due to linguistic constraints. This previous research gives us a benchmark from which to understand variant selection in reported speech utterances, since it established the patterns of variation for these morphological variables in the HOME and SCHOOL datasets. We can compare the use of these variables in the reported speech utterances to determine whether reported speech utterances are more like the HOME or SCHOOL datasets in terms of variant selection and conditioning.

\subsubsection{AM Versus I}

In previous work (Dixon 2017, 2018), I explored variation between two first person singular subject pronouns in the children's speech: I (realized as a range of pronunciations, from $/ \mathfrak{v} /$ to the more SAE-like / ai/) and AM (realized as $/ \mathrm{em} /$ ), with the latter likely etymologically derived from the contraction of $I$ and auxiliary am. In both SCHOOL (Australian English) and HOME (Alyawarr English) contexts, the use of each variant was mainly constrained by the form of the main verb: $\mathrm{V}$ or Ving (and Vbat, a verb ending that has habitual or iterative semantics-see Section 3.4.3 below). Both contexts also shared the same conditioning: the I variant was preferred when preceding V verbs, and the AM variant was preferred when preceding Ving verbs, as in Standard Australian English (and Vbat verbs in the HOME context). The main difference between the HOME and SCHOOL contexts was in the frequencies: I and AM were of about equal frequency in the HOME context, while I was much more frequent than AM in the SCHOOL context.

In the reported speech utterances, there are 35 clauses with a first person singular subject (presented in Table 1). Overall, the I variant is the most frequently used form, with 28 tokens. AM is used just 7 times. This reflects the kind of asymmetry seen in the previous analysis of the SCHOOL dataset. Similarly, the previously variable conditioning pattern shared between HOME and SCHOOL contexts (I preceding V verbs; AM preceding Ving verbs) is also demonstrated here. However, now the pattern is categorical, with the small number of Ving verbs preceded only by AM [N = 3] and all the $\mathrm{V}$ verbs preceded by $\mathrm{I}$ $[\mathrm{N}=23]^{7}$.

Table 1. Distribution of 1sg subject pronouns by main verb form.

\begin{tabular}{ccccc}
\hline Clause Type & I & AM & Examples & \\
\hline $\begin{array}{c}\text { Present temporal ref. } \\
\text { Ving }\end{array}$ & 0 & 3 & I'm going & SJD-069:1232 Sharisha \\
copula & 1 & 4 & I'm done & SJD-069:672 Lorranda \\
V & 23 & 0 & I need to change & SJD-069:1161 Sharisha \\
\hline & 4 & & I saw you & SJD-069:591 Sharisha \\
Past temporal ref. & & 0 & I was just & SJD-069:589 Sharisha \\
& 28 & 7 & & \\
\hline Total & & &
\end{tabular}

Past temporal reference clauses were not included in any prior analysis, so a direct comparison cannot be made. However, a cursory examination of those datasets indicates that the use of the I variant in past tense constructions is categorical in both the HOME and SCHOOL datasets, as found here.

\subsubsection{Transitivity Marking}

Previous work has shown that the children mark transitive verbs with the marker im (Dixon 2017, 2018). They use this feature variably in the HOME data (at around 60\%), and very quickly cease using it in the SCHOOL contexts, for the majority of children within the first 12-24 months of formal schooling. Reported speech data conform to the

\footnotetext{
7 The previous study excluded copula clauses, so I cannot make a comparison of this clause type.
} 
general SCHOOL pattern. Of 89 verbal predicate reported speech clauses, of which 24 were transitive, only 2 were marked with the transitive marker.

These two particular examples (seen in example 9) are also distinct in terms of additional formal and functional features. For example, they lack the special prosodic characteristics detailed above, and contain the contrastive lexical choice of akwapert 'head'. Functionally, this speech occurs after one of the dolls has been manipulated to bump into another of the dolls, whose head has come off. The girls laugh and joke at this, with this instance of reported speech apparently designed to do the latter.

9. leik "Oh sorry I breakim your akwapert!". “I breakim your akwapert, sorry!"

[SJD-069:1071-2 Tiffany]

There are also not many examples of reported speech from Tiffany, only 5 utterances in total. It is not something she uses much in this play session. This is not a matter of lacking the resources, either; Tiffany's L2 English is well-developed, as demonstrated in the SCHOOL data (see also Dixon 2013). I will return to the issue of individual differences in reported speech in the discussion below.

\subsubsection{Verb Morphology}

Previous research has focused specifically on the variation between present temporal reference main verbs in the following three forms: V, Ving and Vbat (Dixon 2017, 2018). While the aspectual semantics of these three forms are beyond the scope of this paper because of the low number of tokens, suffice it to say that the relationship between Ving and Vbat is complex and overlapping, constrained by both verb transitivity and aspectual semantics. However, this previous analysis revealed two important facts about the distribution of these forms in the HOME and SCHOOL contexts that are of use here: (1) Vbat is not used at all in the SCHOOL data; and (2) Ving is used on both transitive and intransitive verbs in the SCHOOL data, whereas it is only used on intransitive verbs in the HOME data (summarized in Table 2).

Table 2. Summary of HOME and SCHOOL verb morphology variable systems.

\begin{tabular}{ccc}
\hline & Home & School \\
\hline Variants & $\mathrm{V} \sim$ Ving $\sim$ Vbat & $\mathrm{V} \sim$ Ving \\
Ving restricted to intransitive verbs & $\boldsymbol{x}$ & $\boldsymbol{x}$ \\
\hline
\end{tabular}

In the reported speech utterances, there are 14 tokens of Ving marked verbs and 37 tokens of plain $\mathrm{V}$ marked verbs, but there are no tokens of verbs marked with -bat. This is despite Vbat verbs appearing 106 times in the play session in non-reported speech utterances. So, in this respect, the reported speech utterances are like the SCHOOL data.

Furthermore, Ving appears not to be restricted to intransitive verbs in the reported speech utterances, as it appears on transitive reported speech clauses in three instances. They are presented here (example "a") with complementary examples of the same verbs marked with $\mathrm{V}$ or Vbat in non-reported speech clauses from the same play session (example "b").

10. a. "I'm doing it."

b. Am duimbat thisan. ('I'm doing this one')

[SJD-069:1314 Alysha]

[SJD-069:887 Alysha]

11. a. "I was just helping you."”

b. Ai gat go elpim. ('I've got to go help (her)')"

[SJD-069:589 Alysha]

[SJD-069:263 Lucy]

12. a. "We are wasting time now."

b. Olot yu weistimbat. ('Whole lot, you are wasting.')

[SJD-069:762 Alysha]

[SJD-007:390 Lucy]

On this factor, the reported speech utterances appear structurally more like the children's other SCHOOL language use than their other HOME language use. 


\subsection{Framing}

One distinct feature of reported speech utterances is that they occur with specific types of framing (also called the "reporting clause" or "reporting utterance" e.g., Haakana 2007). In the present case study, I have classified these into four types: action framing, quotative framing, prior-talk framing and zero framing.

\subsubsection{Action Framing}

In 39 instances of reported speech, the utterance is immediately preceded by the live narrating of the actions of the dolls, as in Extract 5. This starts with the last of a series of utterances (not shown) in which Alysha is describing what her doll is doing. After stating that the doll is looking at all the things (line 266) she moves immediately to several utterances of reported speech.

\section{Extract 5}

Alys Ai bin luk ola thing-rnem na, I looked at all the things now

(.)

In these cases, the reported speech utterances are framed by the narrated actions of the doll personas, and can be understood as progressing the situation set up by the narrated action.

\subsubsection{Quotative Framing}

One well-documented way of framing reported speech is the use of quotatives (e.g., Buchstaller and van Alphen 2012; Rodríguez Louro 2013), that is, a "word/construction signaling reported discourse" (Buchstaller and van Alphen 2012, p. 288). In this play session, 20 of the reported speech utterances are introduced with quotative constructions. The most frequently occurring of these is bin tok, "said" 8 . This is demonstrated in Extract 6 (which is a partial repeat of Extract 1) on line 581.

\section{Extract 6}

581 Alys >En ai bin fain tha ring na reken<, en- ai bin tok, And I found the ring now, reckon, and I said (.)

Alys " "How we gonna put the $\uparrow$ ri: $\downarrow$ ng,"

This can also be followed by a prepositional or adverbial phrase, prior to the reported speech component, as in line 144 of Extract 7.

\section{Extract 7}

There are two instances when this bin tok quotative is reduced even further to just the past auxiliary bin, as in Extract 8. 


\section{Extract 8}

411

Alys Ai bin weitbat, ai bin

I waited I was

412

“决h"

There are two verbs other than talk used in the construction of quotative frames. These are ask "ask" $(\mathrm{N}=1)$ and trai "try" $(\mathrm{N}=1)$. The first is a verb of speech, while the use of trai relates to the specific context of trying to get the other doll to do something.

\subsubsection{Responsive Framing}

The largest portion of reported speech utterances $(\mathrm{N}=76)$ occurs as responsive moves in dialogic sequences, as in Lucy's response (line 597) to Alysha's invitation (line 596), in Extract 9.

\section{Extract 9}

$\begin{array}{rll}594 \quad \text { Alys } & >\text { Ai bin go na, } \\ & \text { I went now } \\ & (.) \\ 596 \quad \text { Alys } & \stackrel{<}{ } \text { "Do you guys wanna swim?"> } \\ & (0.5) \\ 597 \quad \text { Lucy } & \text { "Wait a } \uparrow \text { minute," }\end{array}$

(.)

As such, these types of reported speech utterance often constitute a second pair-part to a prior turn at talk. In this example, there is a question-answer sequence in which Lucy's response is framed by the first pair-part of Alysha's question.

\subsubsection{Zero Framing}

Reported speech utterances do not always get verbalized framing (these have been called "zero quotatives," e.g., Mathis and Yule 1994; Buchstaller and van Alphen 2012, p. 289). In Extract 10, Alysha is narrating some exciting action for her doll (a pending bomb explosion, lines 405 to 407). Lucy notices this and moves her doll closer to Alysha's doll. Lucy produces the reported speech on line 408 without any other verbal framing.

\section{Extract 10}

Alys Ai bin getat na

I got out now

(.)

406 Alys Ai bin lukbat laiya than theya bom reken

I looked, pretend, that one there is a bomb, reckon

(.)

407 Alys I bin redi to ekspl[oud na reken

It is ready to explode now reckon

408 Lucy ["^He: $\downarrow$ y. $\uparrow$ What you doing."

While there is no verbal framing, the movement of Lucy's doll towards Alysha's doll does itself create a context for reported speech to occur. Verbal framing devices, such as the use of quotatives in particular, have this same property, that of preparing the listener for forthcoming reported speech. Drawing on this shared functional property, it is possible to view some kinds of physical manipulation of the dolls as a form of embodied framing.

\subsection{The Function of Reported Speech Utterances}

The central analytic framework of this paper is to illuminate the sets of linguistic elements that cluster in particular functions within these children's multilingual repertoires, as well as to better understand the functions themselves. Therefore, in order to understand 
how reported speech (in the particular way it is structurally constituted) functions as a distinct social activity within these children's repertoires, Research Question \#2 asks: What does selecting from different parts of the multilingual repertoire afford these children in the context of play? In other words, how does crosslinguistic mixing in play constitute, in Matras ([2009] 2020, p. 4) formulation, "effective goal-oriented communication"?

The preceding results sections have presented a sample of some language elements that cohere in the performance of reported speech. It has been shown that the children select from part of their repertoire that contrasts with the surrounding talk (as captured in the analysis of the HOME dataset). The morphological and lexical components of reported speech utterances appear to draw from the same part of the children's repertoire as the SCHOOL dataset. This may be because the dolls are visibly white-skinned, which may be associated with English-speaking for these children. Yet some of these reported speech elements resemble yet diverge from SCHOOL utterances in specific ways (such as Alysha's use of rhoticity), showing that reported speech is not straightforwardly a "switch to English". It is furthermore worth considering other affordances that this particular pairing of social activity (i.e., reported speech) and repertoire selection offers for the children, beyond the construction of the dolls as white English-speakers.

Matras ([2009] 2020, p. 4) notes that the alignment between context and "language" is not strict; "certain types of cross-linguistic 'mixing' and 'inserting' may be socially acceptable and may constitute effective goal-oriented communication". If we take "play" as the context in question, we can look at how the constitution of these reported speech utterances deviates from both the HOME and SCHOOL varieties, in order to show that a unique mix of elements serves certain local communicative needs. For example, as I observed above, the use of rhoticity serves to make the delineation between reported speech and surrounding talk more perceptually salient.

Reported speech (even in multilinguals) need not at all be marked as different from surrounding talk, although people often use a variety of strategies to mark the reported speech stylistically, such as the use of quotatives to introduce direct reported speech, prosodic differences, voice quality, pre-pauses, intonation etc. to other accommodations in indirect reported speech (Romaine and Lange 1991; Holt 2000; Kleemann 2013). People with multilingual repertoires have an additional option to mark reported speech by doing what would traditionally be called code-switching. Accounts of conversational codeswitching from Interactional Linguistics have described code-switching in reported speech as a conversation management tool, and have shown that the language of the reported speech utterance does not necessarily have to match the language of the original utterance being reported. For instance, Gafaranga (2007, p. 155) presents an example from Rwanda in which the speaker code-switches from Kinyarwanda into French, in order to perform the reported speech that was originally delivered in German. Certainly, we could observe that reported speech serves a similar conversation organization function here, marking out the speech of the dolls from surrounding talk.

In addition to this, a close analysis of not only the turns surrounding each instance of reported speech, but also the play session as a whole, reveals another important element of how these reported speech utterances constitute "effective goal-oriented communication", per Matras ([2009] 2020, p. 4). The use of reported speech utterances allows the girls to attempt a range of moves from the vantage of their doll "alter egos"; moves that may be directly sanctioned if performed by the girls themselves. For example, in one sequence Alysha's doll asks if Lucy's doll wants to go swimming, on line 596. Lucy's doll replies, "Wait a minute". Alysha's doll accepts this with, "Alright, wait a minute". Alysha then moves her doll near Deanna's doll, and repeats the question, "You guys wanna swim?". Deanna also rejects this with, "Not yet wait a minute" on line 602. 


\section{Extract 11}

\begin{tabular}{|c|c|c|}
\hline 594 & Alys & $\begin{array}{l}>\text { Ai bin go na, }< \\
\text { I went now } \\
\text { (.) }\end{array}$ \\
\hline 596 & Alys & $\begin{array}{l}<" \text { Do you guys wanna swim?"> } \\
(0.5)\end{array}$ \\
\hline 597 & Lucy & $\begin{array}{l}\text { “Wait a } \uparrow \text { minute," } \\
\text { (.) }\end{array}$ \\
\hline 598 & Alys & $\begin{array}{l}\text { "Alright. (.) } \downarrow^{\circ} \text { Wait a minute }{ }^{\circ} . " \\
(0.4)\end{array}$ \\
\hline 600 & Alys & "You guys [wanna swim?" \\
\hline 601 & Lucy & $\begin{array}{l}\text { [Mai mami bin [tok reken. } \\
\text { My mummy said, reckon }\end{array}$ \\
\hline & Dea & ["Not yet wait a minu \\
\hline
\end{tabular}

This sequence can be understood on two levels: things the dolls are doing, and things the girls are doing. On one level, the doll level, they just acted out one doll asking the other dolls to do something and being rejected. This could potentially be part of a larger story of conflict or being the outcast. At various times the girls do indeed act out the dolls having conflict as part of the little scenes they play out. However, note that this is different from the girls themselves being in conflict-this takes other forms in the "out-of-play" sequences.

On another level, the girl level, Alysha's turns at lines 596 and 600 are suggesting a course of play for the girls to act out. Thus, making her doll say, "Do you wanna swim?" is another way for Alysha to say to Lucy and Deanna, "Let's now play out a sequence in which we all go swimming." Lucy's and Deanna's rejection of this is also done in the form of reported speech, which perhaps lessens the rejection, as it is accomplished via the dolls rather than directly.

In this respect, reported speech utterances function as part of a larger agenda that is the management of authority and "epistemic rights" (Sidnell 2011), or who gets to know what, in the course of play. Each child has the right to know what is in the mind of her own doll, and what her doll wants to do and will do. Actions that impact on others and therefore have the potential to steer the course of play have to be negotiated, and this entails different linguistic work. For example, Extract 12 opens with Lucy narrating what her doll is doing. This is spoken on line 784 as a simple declarative. On the following line (785), Lucy states that her doll stops next to Deanna's doll, thereby involving her in the unfolding action. Instead of producing a plain declarative, she inserts reken, "reckon", which appears to transform the utterance into more of a proposition. On her quickly following next utterances (line 787) Lucy makes a direct assertion about Deanna's doll: "You didn't see our dress." This is strongly objected to by Deanna, who produces a long "no" at line 788, followed up by a fairly token account ("I just wanna thing").

This contrasts with the interactional work done on line 792, where Alysha makes a suggestion involving Lucy's doll (that they are sitting together). This utterance is formulated with the lexeme laiya, "pretend" and the tag question nanti. The lexeme laiya appears to function in ways similar to that of pretend in English, that is, to construct proposals in imaginative play contexts (Sidnell 2011; Pleyer 2019). The tag question explicitly invites agreement (or at least a response) from the addressee. This arrives in line 793, with Lucy's production of two oral clicks, which signifies agreement in this community. 


\section{Extract 12}

\begin{tabular}{|c|c|c|}
\hline 784 & Lucy & $\begin{array}{l}\text { Ai bin go swim na } \\
\text { I went to swim now }\end{array}$ \\
\hline 785 & Lucy & $\begin{array}{l}\text { Ai bin stop weya:- thet skin-mab theya reken thet gel-rnem } \\
\text { theya= } \\
\text { And I stopped where-that skin-colored group reckon, those girls } \\
\text { there }\end{array}$ \\
\hline 786 & Aly & $\begin{array}{l}=y e: \text { minyu bin laiya [sitapbat na- } \\
\text { Yeah, pretend we are sitting }\end{array}$ \\
\hline 787 & Lucy & $\begin{array}{l}\text { [Yumab neba luk wimab-kenh [dres na } \\
\text { You didn't see our dress }\end{array}$ \\
\hline 788 & Dea & $\begin{array}{l}{[\mathrm{NO}:::} \\
(0.2)\end{array}$ \\
\hline 789 & Dea & $\begin{array}{l}\text { Ana jes thing }= \\
\text { I just wanna thing }\end{array}$ \\
\hline 790 & Lucy & $\begin{array}{l}=\text { yumab na- thei neba luk minyus dres } \\
\text { You didn't- they didn't see our dress }\end{array}$ \\
\hline 791 & Dea & $(\quad)$ \\
\hline 792 & Aly & $\begin{array}{l}\text { En minyu bin laiya sitapbat nanti } \\
\text { And pretend we're sitting, aren't we }\end{array}$ \\
\hline & Lucy & $(($ clicks $))$ \\
\hline
\end{tabular}

This Extract shows that these girls are acutely aware of the epistemic landscape of the play space, and co-construct this reality in part by how they talk about what they themselves and the other dolls are doing. Reported speech plugs into this repertoire, in that it falls within the sphere of "things I can say about myself but not (straightforwardly) about others, and that others can say about themselves but not (straightforwardly) about me." It does not get sanctioned, "you didn't say that", nor do the girls tend to enact reported speech for others' dolls. Presenting a suggested direction of play as reported speech ("Do you wanna swim?" versus, e.g., "Pretend we're going swimming now, I reckon") is therefore part of a suite of moves that are designed to mobilize the other girls into a course of action. In doing this, it can be seen as "effective goal-oriented communication" in that it accomplishes several goals at once: it organizes talk-in-interaction, and it manages the social relationships of the play participants. A similar "duality" of purpose has been noted in adult English-speakers' use of reported speech (Holt 2000).

\section{Discussion}

The preceding analysis of the functional and structural dimensions of the children's reported speech utterances has revealed some important facets of the multilingual repertoires of this cohort of Alyawarr children. Firstly, reported speech in pretend play does appear to be a specific social activity (as evidenced by the analysis of its functional affordances), and as such can be understood as part of the fabric of social activities that have become associated with a specific set of cohering linguistic elements from the multilingual repertoire.

Secondly, some of these linguistic elements also cohere in other social activities, such as talking to a teacher at school (as captured in the comparison to the SCHOOL data). However, some of these elements are novel (e.g., Alysha's use of rhoticity) or potentially language non-specific, echoing previous research on the structural distinctness of reported speech in both multilingual and monolingual talk. For example, raised pitch is a characteristic of Sámi-Norwegian bilingual children's "play-voice", the children's "rendition of so-called 'standard Norwegian'" that is used when speaking in role-play characters (Kleemann 2013, p. 63). Raised pitch and exaggerated intonation are also noted in the L2 English reported speech in role-play utterances of Finnish-English bilingual children (Halmari and Smith 1994). Taken together, this evidences multilingual children's 
ability to not only select elements from their language repertoire in order to perform reported speech in play, but also that the resultant coherent whole of a child's multilingual repertoire is somewhat more than a set of neatly delineated, bounded, varieties.

Thirdly, these children select from their multilingual repertoires not only on the basis of aspects of the macro-social context (i.e., setting, interlocutor), but also based on the need to achieve local conversation organizational ends (i.e., the management of their dolls' voices through the use of reported speech), as well as the complexities of epistemic management. While the literature has explored in some detail the reasons constraining the language choices of multilingual adults (as attested in the vast literature on 'code-switching' and 'code choice'), fewer studies have examined this aspect of children's repertoire management (however, see McClure (1981); Fotos (1990); Reyes (2004); and Shin (2014)), and none in the context of an Australian language community. This finding thus contributes important evidence of the ability of quite young children to manipulate their repertoires to achieve a variety of types of ends. This also opens a promising new direction in the exploration of Australian Indigenous children's language use in peer interaction as so far contained in the small but growing body of literature on the topic (see Rendle-Short and Moses (2010); Dixon (2015); Davidson (2018); Watts et al. (2019)). This finding also suggests that the initial broad partitioning of the corpus data that gave rise to the HOME and SCHOOL dataset may need to be revisited for a more refined set of social activities that could account for some of the internal variation within these datasets.

Finally, before concluding this paper, I will make a few observations about the individual in the context of these findings, not only in consideration of a potential limitation of this study, but also as an interesting reality of the participant cohort. Matras ([2009] 2020, p. 4) invites us to consider the processes of "linguistic socialization" that bring about the association between the structural elements outlined above. In the present play session, as I have noted, the use of reported speech utterances (with the elements discussed above) is dominated by Alysha (see Table 3 below) ${ }^{9}$. Lucy and Deanna both use the elements noted above, so along with Alysha they use a "coherent" variety in the construction of reported speech. By contrast, Tiffany's reported speech utterances at several points do not conform to the variant choice of the other children (she uses transitive marking and Alyawarr-derived lexemes, for example). At one point, she even subverts the very idea of the dolls "speaking" at one point, laughingly saying, "Hey you not the Sarah (Alysha's doll's name), you the Alysha". As I noted above, this is not because she does not have control over these elements. This also contrasts somewhat with other earlier recordings, where she acts out being a schoolteacher at home and uses the reported features described here when talking as a teacher. It could just be that she did not feel the same way on this day.

Table 3. Number of reported speech utterances per child.

\begin{tabular}{cc}
\hline Child & Number of Reported Speech Utterances \\
\hline Alysha & 140 \\
Lucy & 44 \\
Deanna & 8 \\
Tiffany & 5 \\
\hline
\end{tabular}

Furthermore, the asymmetry between the girls in the quantity of use of reported speech in this play session points to the fact that the process of linguistic socialization that leads to these girls associating the structural features outlined above with the performance of reported speech is one in which children socialize each other into such associations. Alysha seems to be the main user of reported speech on this occasion, although the other girls clearly recognize what she is doing, even if they participate in it to a lesser extent. Alysha is not the oldest child in the group, but she is the more socially dominant and is to

9 A table with the contribution of each child to the linguistic elements discussed in the Results section appears in Appendix A. 
some extent interactionally skillful of this group (as shown in other research around the construction of ownership in play, see Dixon (2015)). Moreover, each of these girls will sometimes play with younger children in the community, wherein lies the opportunities to expose other children to the repertoire of language use developed in this play session.

The use of multilingual repertoire to enact and voice toys in play (and indeed the very landscape of epistemic and other rights) is one of those aspects of child culture that children learn from other children, and in turn socialize other children into the practice before outgrowing it. Investigations of peer culture in childhood show that many aspects of children's language-mediated lives display this trait, from the transmission of singing games (e.g., Marsh 1997) to the complex rule structures of interactive play (e.g., Cobb-Moore et al. 2008; Maynard 1985).

In their discussion of coherence in the context of language change, Guy and Hinskens (2016, p. 4) ask, "How much do members of a speech community really share, and what does this mean for the very definition of a speech community, a dialect, or a language?" and, consequently, "At which point do we want to talk about a separate variety?". For the girls in this study (and in previous quantitative studies exploring their language use), having a shared repertoire of linguistic elements, as well as selecting from this repertoire the same clusters of elements to perform various social actions (to talk to teachers in school, to argue at home, to do reported speech in imaginative play), is how they are constituted as a speech community. The elements in their repertoire do not seem to be delineated by strict boundaries such that we might identify separate "varieties". Rather, we have arrived back at the idea that the multilingual repertoire is more than the sum of its parts.

\section{Conclusions}

This study has shown that in these children's repertoires, the voicing of a doll's speech is a social activity that has become associated with a set of prosodic, phonological, lexical, morphological and discourse organizational elements. These elements contrast with functionally equivalent elements in the surrounding talk, and to some extent to the set of elements chosen when speaking to non-Indigenous teachers at school. When deployed in the context of playing with dolls, reported speech constitutes a case of cross-linguistic mixing that constitutes "effective goal-oriented communication" that manages both the talk-in-interaction and the social relationships of the interactants. Children in Ipmangker socialize each other into forming the association between the set of linguistic elements outlined and the context of reported speech. This investigation of reported speech, from both a structural and functional perspective, has provided rich insight into the complex social work that is achieved via linguistic choices as part of everyday play.

Funding: This research was partly funded by The Australian Research Discovery Grant, grant number DP0877762.

Institutional Review Board Statement: The study was approved by the Human Research Ethics Committee) of The University of Melbourne (HREC number 0931926.1 20/05/09).

Informed Consent Statement: Informed consent was obtained from all subjects involved in the study.

Data Availability Statement: Data supporting the results are not publicly available at this time, due to the nature of the agreement with participants to protect the privacy of the participating children. Enquiries about data can be made direct to the author.

Acknowledgments: I wish to acknowledge the contribution of research assistants Ms Linda Dobbs, Ms Michelle Dobbs and the late Ms G. Kelly, who facilitated this research in myriad ways such as excellent transcription and translation support. I also gratefully acknowledge and thank the participating children and their families, who allowed us to eavesdrop on their lives.

Conflicts of Interest: The author declares no conflict of interest. 


\section{Appendix A}

Table A1. Alyawarr-derived lexemes in the play session.

\begin{tabular}{cccc}
\hline POS & Lexeme & Frequency \\
\hline Noun & akwapert & "head" & 19 \\
& mwekart & "hat" & 16 \\
antyeny & "dude" & 12 \\
aylpaty & "breast" & 7 \\
irrepern & "poor thing" & 4 \\
& anngwelty & "tear" & 2 \\
kuna & "poo" & 1 \\
& kwaty & "water" & 1 \\
& Antarringeny & (placename) & 1 \\
arew & "look" & 3 \\
& angwarey & "want" & 1 \\
& nakey & "show-off" & 1 \\
& pwertew & "look-out" & 1 \\
& rakey & "grab" & 1 \\
& ywerrew & "disappear" & 1 \\
Adjective & akely & "little" & 31 \\
& ilkwa & "big" & 9 \\
ahelengkw & "mad" & 2 \\
& alakenh & "like that" & 60 \\
& Ingkartek & "for god" & 12 \\
Adverb & yew & "yes" & 6
\end{tabular}

Table A2. Number of tokens of each linguistic element, per child.

\begin{tabular}{|c|c|c|c|c|c|c|c|c|c|}
\hline \multirow[t]{2}{*}{ Child } & \multirow{2}{*}{$\begin{array}{c}\text { Number of } \\
\text { Reported Speech } \\
\text { Utterances }\end{array}$} & \multirow{2}{*}{$\begin{array}{l}\text { Use of } \\
\text { Prosodic } \\
\text { Features }\end{array}$} & \multirow{2}{*}{$\begin{array}{l}\text { Use of Alyawarr- } \\
\text { Derived } \\
\text { Lexicon }\end{array}$} & \multicolumn{2}{|c|}{ 1sg Sub Pronoun } & \multirow{2}{*}{$\begin{array}{l}\text { Transitivity } \\
\text { Marking }\end{array}$} & \multicolumn{3}{|c|}{ Verb Morphology } \\
\hline & & & & I & $\mathrm{AM}$ & & $\mathrm{V}$ & Ving & Vbat \\
\hline Alysha & 140 & 140 & 0 & 17 & 4 & 0 & 21 & 11 & 0 \\
\hline Lucy & 44 & 44 & 0 & 8 & 2 & 0 & 12 & 3 & 0 \\
\hline Deanna & 8 & 8 & 0 & 1 & 1 & 0 & 2 & 0 & 0 \\
\hline Tiffany & 5 & 5 & 2 & 2 & 0 & 2 & 2 & 0 & 0 \\
\hline
\end{tabular}

\section{References}

Alvarez-Cáccamo, Celso. 1998. From 'switching code' to 'code-switching': Towards a reconceptualisation of communicative codes. In Code-Switching in Conversation. Language, Interaction and Identity. Edited by Peter Auer. London: Routledge, pp. 29-50.

Auer, Peter. 1984. Bilingual Conversation. Amsterdam: John Benjamins.

Auer, Peter. 1995. The pragmatics of code-switching: A sequential approach. In One Speaker, Two Languages: Cross-Disciplinary Perspectives on Code-Switching. Edited by Lesley Milroy and Pieter Muysken. Cambridge: Cambridge University Press, pp. 115-35.

Brandl, Maria M., and Michael Walsh. 1982. Speakers of many tongues: Toward understanding multilingualism among Aboriginal Australians. International Journal of the Sociology of language 36: 71-81. [CrossRef]

Buchstaller, Isabelle, and Ingrid van Alphen, eds. 2012. Quotatives: Cross-Linguistic and Cross-Disciplinary Perspectives. Amsterdam: John Benjamins.

Clift, Rebecca. 2006. Indexing stance: Reported speech as an interactional evidential1. Journal of Sociolinguistics 10: 569-95. [CrossRef]

Clift, Rebecca. 2007. Getting there first: Non-narrative reported speech in interaction. In Reporting Talk: Reported Speech in Interaction. Edited by Elizabeth Holt and Rebecca Clift. Cambridge: Cambridge University Press, pp. 120-49.

Cobb-Moore, Charlotte, Susan Danby, and Ann Farrell. 2008. 'I told you so': Justification used in disputes in young children's interactions in an early childhood classroom. Discourse Studies 10: 595-614. [CrossRef]

Couper-Kuhlen, Elizabeth. 2007. Assessing and Accounting. In Reporting Talk: Reported Speech in Interaction. Edited by Elizabeth Holt and Rebecca Clift. Cambridge: Cambridge University Press, pp. 81-119.

Cox, Felicity, and Sallyanne Palethorpe. 2007. Australian English. Journal of the International Phonetic Association 37: 341-50. [CrossRef]

Crowley, Terry, and Bruce Rigsby. 1979. Cape York Creole. In Languages and Their Status. Edited by Tim Shopen. Philadelphia: University of Pennsylvania Press, pp. 153-207. 
Davidson, Lucinda. 2018. Allies and Adversaries: Categories in Murrinhpatha Speaking Children's Talk. Melbourne: The University of Melbourne.

Disbray, Samantha. 2008. Storytelling styles: A study of adult-child interactions in narrations of a picture book in Tennant Creek. In Children's Language and Multilingualism: Indigenous Language Use at Home and School. Edited by Jane Simpson and Gillian Wigglesworth. London: Continuum, pp. 56-78.

Dixon, Robert M. W. 2002. The Australian Languages: Their Nature and Development. Cambridge: Cambridge University Press.

Dixon, Sally. 2009-2011. Ipmangker Corpus of Multilingual Child Interaction. Aboriginal Child Language Acquisition 2 Project. Melbourne: The University of Melbourne, Available online: https:/ / arts.unimelb.edu.au/school-of-languages-and-linguistics/research/ past-research-projects/acla2 (accessed on 1 November 2020).

Dixon, Sally. 2013. Educational failure or success: Aboriginal children's non-standard English utterances. Australian Review of Applied Linguistics 36: 302-15. [CrossRef]

Dixon, Sally. 2015. Gimme! Gimme! Gimme!: Object requests, ownership and entitlement in a children's play session. Journal of Pragmatics 83: 39-51. [CrossRef]

Dixon, Sally. 2017. Alyawarr Children's Variable Present Temporal Reference Expression in Two, Closely-Related Languages of Central Australia. Canberra: The Australian National University.

Dixon, Sally. 2018. Alyawarr children's Use of two closely-related languages. In Language Practises of Indigenous Children and Youth: The Transition from Home to School. Edited by Gillian Wigglesworth, Jane Simpson and Jill Vaughan. London: Palgrave Macmillan, pp. 271-300.

Eades, Diana. 2014. Aboriginal English. In The Languages and Linguistics of Australia: A Comprehensive Guide. Edited by Harold Koch and Rachel Nordlinger. Berlin and Boston: De Gruyter Mouton, pp. 417-48.

Elwell, Vanessa M. R. 1977. Multilingualism and Lingua Francas among Australian Aborigines: A Case Study of Maningrida. Canberra: Australian National University.

Elwell, Vanessa M.R. 1982. Some factors affecting multilingualism among Aboriginal Australians. International Journal of the Sociology of language 36: 83-104.

Evans, Nicholas. 2010. A tale of many tongues: Polyglot narrative in north Australian oral traditions. Indigenous Language and Social Identity: Papers in Honour of Michael Walsh. Pacific Linguistics 626: 275-95.

Fotos, Sandra S. 1990. Japanese-English Code Switching in Bilingual Children. JALT Journal 12: 75-98.

Frick, Maria, and Helka Riionheimo. 2013. Bilingual voicing: A study of code-switching in the reported speech of Finnish immigrants in Estonia. Multilingua 32: 565-99. [CrossRef]

Gafaranga, Joseph. 2007. Talk in Two Languages. London: Palgrave Macmillan.

García, Ofelia, and Li Wei. 2014. Translanguaging: Language, Bilingualism and Education. London: Palgrave Macmillan.

Genesee, Fred, Elena Nicoladis, and Johanna Paradis. 1995. Language differentiation in early bilingual development. Journal of Child Language 22: 611-31. [CrossRef] [PubMed]

Goffman, Erving. 1981. Footing. In Forms of Talk. Edited by Erving Goffman. Hoboken: Blackwell, pp. 124-59.

Gumperz, John J. 1964. Linguistic and Social Interaction in Two Communities. American Anthropologist 66: 137-53. [CrossRef]

Gumperz, John J. 1982. Discourse Strategies. Cambridge: Cambridge University Press.

Gumperz, John J. 1991. Introduction. In Directions in Sociolinguistics: The Ethnography of Communication. Edited by John J. Gumperz and Dell H. Hymes. London: Blackwell, pp. 1-25. First published 1972.

Guy, Gregory R., and Frans Hinskens. 2016. Linguistic coherence: Systems, repertoires and speech communities. Lingua 172-73: 1-9. [CrossRef]

Haakana, Markku. 2007. Reported thought in complaint stories. In Reporting Talk: Reported Speech in Interaction. Edited by Elizabeth Holt and Rebecca Clift. Cambridge: Cambridge University Press, pp. 150-78.

Halmari, Helena, and Wendy Smith. 1994. Code-switching and register shift: Evidence from Finnish-English child bilingual conversation. Journal of Pragmatics 21: 427-45. [CrossRef]

Harris, John. 2007. Linguistic responses to contact: Pidgins and Creoles. In The Habitat of Australia's Aboriginal Languages. Edited by Gerhard Leitner and Ian G. Malcolm. Berlin and New York: Mouton De Gruyter, pp. 131-51.

Holt, Elizabeth, and Rebecca Clift, eds. 2007. Reporting Talk: Reported Speech in Interaction. Cambridge: Cambridge University Press.

Holt, Elizabeth. 2000. Reporting and reacting: Concurrent responses to reported speech. Research on Language and Social Interaction 33: 425-54. [CrossRef]

Holt, Elizabeth. 2009. Reported Speech. In Handbook of Pragmatics. Amsterdam: John Benjamins, pp. 1-20.

Hutchby, Ian, and Robin Wooffitt. 1998. Conversation Analysis Principles, Practices, and Applications. Cambridge: Polity Press.

Kleemann, Carola. 2013. Play in two languages. Language alternation and code-switching in role-play in North Sámi and Norwegian. Nordlyd 39: 47-69. [CrossRef]

Koch, Harold. 2000. Central Australian Aboriginal English: In comparison with the morphosynticatic categories of Kaytetye. Asian Englishes: An International Journal of the Sociolinguistics of English in Asia/Pacific 3: 32-58. [CrossRef]

Labov, William. 1972. Sociolinguistic Patterns. Philadelphia: University of Pennsylvania Press.

Labov, William. 2006. The Social Stratification of English in New York. Cambridge: Cambridge University Press. First published 1966.

Levinson, Stephen C. 1988. Putting linguistics on a proper footing: Explorations in Goffman's concepts of participation. In Erving Goffman: Exploring the Interaction Order. Edited by Paul Drew and Anthony J. Wootton. Berlin: Mouton De Gruyter, pp. $29-45$. 
Li, Wei, and Lesley Milroy. 1995. Conversational code-switching in a Chinese community in Britain: A sequential analysis. Journal of Pragmatics 23: 281-99. [CrossRef]

Makoni, Sinfree, and Alistair Pennycook. 2007. Disinventing and Reconstituting Languages. In Disinventing and Reconstituting Languages. Edited by Sinfree Makoni and Alistair Pennycook. Bristol: Multilingual Matters, pp. 1-41.

Malcolm, Ian G., and Susan Kaldor. 1991. Aboriginal English: An overview. In Language in Australia. Edited by Suzanne Romaine. Cambridge: Cambridge University Press, pp. 67-83.

Marsh, Kathryn M. 1997. Variation and Transmissin Processes in Children's Singing Games in an Australian Playground. Sydney: The University of Sydney.

Mathis, Terrie, and George Yule. 1994. Zero quotatives. Discourse Processes 18: 63-76. [CrossRef]

Matras, Yaron. 2020. Language Contact. Cambridge: Cambridge University Press. First published 2009.

Maynard, Douglas W. 1985. On the Functions of Social Conflict Among Children. American Sociological Review 50: 207-23. [CrossRef]

McClure, Erica. 1981. Formal and functional aspects of the codeswitched discourse of bilingual children. In Latino Language and Communicative Behavior. Edited by Richard Duran. Norwood: Ablex, pp. 69-94.

McConvell, Patrick. 2008. Mixed languages as outcomes of code-switching: Recent examples from Australia and their implications. Journal of Language Contact 2: 187-212. [CrossRef]

McKay, Graham R. 2007. Language maintenance, shift-And planning. In The Habitat of Australia's Aboriginal Languages. Edited by Gerhard Leitner and Ian G. Malcolm. Berlin and New York: Mouton De Gruyter, pp. 101-30.

Meakins, Felicity, and Carmel O'Shannessy, eds. 2016. Loss and Renewal: Australian Languages Since Colonisation. Berlin: De Gruyter Mouton.

Meakins, Felicity. 2007. Case-Marking in Contact: The Development and Function of Case Morphology in Gurindji Kriol, an Australian Mixed Language. Melbourne: University of Melbourne.

Meakins, Felicity. 2015. From absolutely optional to only nominally ergative: The life cycle of the Gurindji ergative suffix. In Borrowed Morphology. Edited by Francesco Gardani, Peter Arkadiev and Nino Amiridze. Berlin: De Gruyter.

Meakins, Felicity. 2020. Beyond apparent time: Generation as a distinct social category. Paper presented at Australian Linguistics Society Online Conference, December 14-15.

Mushin, Ilana. 2010. Code-Switching as an Interactional Resource in Garrwa/Kriol Talk-in-Interaction. Australian Journal of Linguistics 30: 471-96. [CrossRef]

O'Shannessy, Carmel. 2013. The role of multiple sources in the formation of an innovative auxiliary category in Light Warlpiri, a new Australian mixed language. Language 89: 328-53. [CrossRef]

O'Shannessy, Carmel. 2015. Multilingual children increase language differentiation by indexing communities of practice. First Language 35: 305-26. [CrossRef]

Otsuji, Emi, and Alastair Pennycook. 2011. Social inclusion and metrolingual practices. International Journal of Bilingual Education and Bilingualism 14: 413-26. [CrossRef]

Pleyer, Michael. 2019. The Everyday Use of pretend in Child Language and Child-Directed Speech: A Corpus Study. Heidelberg: Universität Heidelberg.

Poplack, Shana, and Sali A. Tagliamonte. 2001. African American English in the Diaspora. Malden and Oxford: Blackwell.

Rendle-Short, Johanna, and Karin Moses. 2010. Taking an Interactional Perspective: Examining Children's Talk in the Australian Aboriginal Community of Yakanarra. Australian Journal of Linguistics 30: 397-421. [CrossRef]

Reyes, Iliana. 2004. Functions of Code Switching in Schoolchildren's Conversations. Bilingual Research Journal 28: 77-98. [CrossRef]

Rodríguez Louro, Celeste. 2013. Quotatives down under: Be like in cross-generational Australian English speech. English World-Wide 34: 48-76. [CrossRef]

Romaine, Susanne, and Deborah Lange. 1991. The Use of like as a Marker of Reported Speech and Thought: A Case of Grammaticalization in Progress. American Speech 66: 227-79. [CrossRef]

Rumsey, Alan. 2018. The sociocultural dynamics of indigenous multilingualism in northwestern Australia. Language E Communication 62: 91-101. [CrossRef]

Schegloff, Emanuel A. 1984. On some questions and ambiguities in conversation. In Structures of Social Action. Edited by J. Maxwell Atkinson and John Heritage. Cambridge: Cambridge University Press, pp. 28-52.

Schultze-Berndt, Eva, Felicity Meakins, and Denise Angelo. 2013. Kriol. In The Survey of Pidgin and Creole Languages. Edited by Susanne Michaelis, Philippe Maurer, Magnus Huber and Martin Haspelmath. Oxford: Oxford University Press, pp. 241-51.

Sellwood, Juanita, and Denise Angelo. 2013. Everywhere and nowhere: Invisibility of Aboriginal and Torres Strait Islander contact languages in education and Indigenous language contexts. Australian Review of Applied Linguistics 36: 250-66. [CrossRef]

Shin, Sarah J. 2014. Developing in Two Languages: Korean Children in America. Bristol: Multilingual Matters, vol. 5.

Shnukal, Anna. 1991. Torres Strait Creole. In Language in Australia. Edited by Susanne Romaine. Cambridge: CUP, pp. 180-94.

Sidnell, Jack. 2011. The epistemics of make-believe. In The Morality of Knowledge in Conversation. Edited by Jakob Steensig, Lorenza Mondada and Tanya Stivers. Cambridge: Cambridge University Press, pp. 131-56.

Singer, Ruth, and Salome Harris. 2016. What practices and ideologies support small-scale multilingualism? A case study of Warruwi Community, northern Australia. International Journal of the Sociology of Language 2016: 163-208. [CrossRef]

Spronck, Stef, and Tatiana Nikitina. 2019. Reported speech forms a dedicated syntactic domain. Linguistic Typology 23: 119-59. [CrossRef] 
Theobald, Maryanne, and Susan Danby. 2012. "A Problem of Versions": Laying Down the Law in the School Playground. In Disputes in Everyday Life: Social and Moral Orders of Children and Young People. Edited by Danby Susan and Theobald Maryanne. Bingley: Emerald Group Publishing Limited, pp. 221-41.

Torres-Cacoullos, Rena, and Catherine Travis. 2018. Bilingualism in the Community: Code-switching and Grammars in Contact. Cambridge: Cambridge University Press.

Vaughan, Jill. 2018. "We talk in saltwater words": Dimensionalisation of dialectal variation in multilingual Arnhem Land. Language E Communication 62: 119-32. [CrossRef]

Watts, Janet, Rod Gardner, and Ilana Mushin. 2019. Da Symbol Dat Under da Stuffs: Teaching the Language of Maths to Aboriginal Learners of Standard Australian English as a Second Dialect. The Australian Journal of Indigenous Education 48: 66-78. [CrossRef]

Wilson, Aidan, Peter Hurst, and Gillian Wigglesworth. 2018. Code-switching or code-mixing? Tiwi Children's Use of Language Resources in a Multilingual Environment. In Language Practises of Indigenous Children and Youth: The Transition from Home to School. Edited by Gillian Wigglesworth, Jane Simpson and Jill Vaughan. London: Palgrave Macmillan, pp. 119-46.

Yallop, Colin. 1977. Alyawarra: An Aboriginal Language of Central Australia. Canberra: Australian Institute of Aboriginal Studies. 